\title{
As notas do período militar de Nietzsche: Para uma reavaliação das influências de juventude
}

\author{
João Pereira da Silva Neto*
}

Resumo: Para a elaboração de sua crítica da questão teleológica Nietzsche parte de uma leitura particular das filosofias de Kant, Albert Lange e Schopenhauer. Mais especificamente, sua argumentação em torno da concepção teleológica de mundo, que se constitui em um tema de importância significativa para o posterior desenvolvimento de sua concepção de conhecimento, é fundamentada em uma releitura das posições de Kant e Schopenhauer a partir de uma fundamentação científica. Este posicionamento mais próximo da ciência, uma conquista oriunda da leitura de A História do Materialismo, atua como contraponto às opiniões filosóficas com que Nietzsche entra em contato em sua juventude.

Palavras-chave: Schopenhauer, conhecimento, criação, verdade, teleologia.

* Universidade Federal do Ceará, Fortaleza, Ceará, Brasil.

ORCID https://orcid.org/0000-0002-7625-4248

Correio eletrônico: jpsfilosofia@gmail.com 


\section{A crítica nietzschiana a Kant e Schopenhauer como crítica à teleologia}

Em uma carta de 03 de abril de 1868, dirigida a Erwin Rohde, Nietzsche faz uma declaração a seu amigo acerca da possibilidade de doutorar-se em filosofia, possibilidade que, embora não levada a termo pelo autor, legou à posteridade uma série de notas preparatórias, cuja interpretação traz importantes consequências para o estudo do perspectivismo nietzschiano, como veremos a seguir. $\mathrm{Na}$ carta em questão deparamo-nos com a seguinte afirmação do jovem Nietzsche: "Ademais, tenho pensado que poderia doutorar-me também um dia em filosofia e, assim, justificar posteriormente minha carteira de estudante em Bonn e Leipzig onde sempre perambulava como stud. philos" (KSB II, pág. 265) ${ }^{1}$. Ou seja, muito precocemente o jovem estudante de filologia clássica de Bonn demonstra interesse em vir a doutorar-se em filosofia, disciplina que já lhe havia despertado profunda curiosidade, especialmente após seu contato com a obra de Schopenhauer. A indicação de que o jovem estudante realmente se interessava pelo tema, e de que já realizara alguns preparativos em adiantamento, volta a aparecer em uma menção a este trabalho em outra correspondência, dessa vez em uma carta endereçada a Paul Deussen (KSB II, pág. 269), escrita alguns dias após a carta acima mencionada:

Quando você, a propósito, receber ao final deste ano minha tese de doutorado, perceberá que o problema dos limites do conhecimento se explica em diversos pontos. Meu tema é "o conceito de orgânico desde Kant", metade filosófico, metade ciência da natureza (halb philosophisch,

1 No original: "Übrigens hat mich dies auf den Einfall gebracht, auch einmal philosophisch zu promovieren und so meiner Studentenkarte in Bonn und Leipzig noch nachträglich zu ihrem Rechte zu verhelfen; ich bin nämlich immer als stud. philos. spazieren gegangen". (KSB, II, p. 265). Curt Paul Janz, naquela que é possivelmente a biografia mais celebrada de Nietzsche, comenta que nesta época este cogitara abandonar os estudos de filosofia para dedicar-se às ciências naturais. C. P. Janz,1984, p. 208.

86 | Cad. Nietzsche, Guarulhos/Porto Seguro, v.41, n.2, p. 85-115, maio/agosto, 2020. 
As notas do período militar de Nietzsche: Para uma reavaliação...

halb naturwissenschaftlich). Meus preparativos (Vorarbeiten) já estão quase concluídos. (KSB, II, p. 269). ${ }^{2}$

Com isso, pode-se deduzir que o que era apenas uma ideia vaga, viera a tornar-se um projeto estruturado. Nietzsche, que há muito demonstra certas inquietações filosóficas, e que com a leitura de Schopenhauer e Lange se torna especialmente interessado na filosofia de Kant, anuncia a intenção em aprofundar-se em questões específicas que, por força da influência das interpretações daqueles autores, agora relaciona com a filosofia kantiana. $\mathrm{O}$ filósofo deixa entrever em seus planos para a dissertação elementos fundamentais de uma abordagem do problema do conhecimento. Entre estes elementos, destaca-se o fato de que tal dissertação partiria do ponto de vista de um estudo dos limites dos órgãos da sensibilidade humana. Com isso, além de esclarecer o sentido de sua interpretação da filosofia kantiana, esse trabalho também possibilita uma compreensão precisa acerca de suas preocupações filosóficas naquele período de seu pensamento.

A redação das notas preparatórias para essa possível tese tem nas reflexões de Kant e Schopenhauer uma inspiração contínua. O diferencial da interpretação nietzschiana neste ponto, em grande medida, se deve ao recurso constante às conclusões trazidas para o debate pelas descobertas das ciências naturais. Ou seja, a novidade da abordagem nietzschiana se explica em parte no caráter semicientífico que o autor pretendia conferir a sua tese.

Na medida em que a crítica a toda forma de teleologia presente nessas notas baseia-se em uma consideração do caráter antropomórfico

\footnotetext{
2 Apesar de declarar que seus preparativos encontravam-se já bastante adiantados, considerando-se a relação de Nietzsche com Deussen, seria plausível especular que o autor da carta estivesse contando vantagem de seus planos filosóficos que, na verdade, encontravam-se ainda longe de ser concluídos, sendo que algumas de suas partes ainda encontravam-se em seus estágios iniciais, como demonstra o estado das notas que nos foram legadas. Vale ainda ressaltar que esta correspondência, denuncia um interesse fortíssimo de Nietzsche pelos resultados de sua leitura de A História do Materialismo de Albert Lange, de cujas ideias a dissertação planejada pelo filósofo encontra-se fartamente permeada.
} 
da própria ideia de conveniência a fins ${ }^{3}$, a interpretação kantiana apareceria como modelo de uma forma ingênua de interpretação teleológica, por desconsiderar a atuação do intelecto na formação daquilo que compreendemos como a ideia de organismo. Nessa crítica, o autor acompanha de perto a Schopenhauer, a quem se refere, ao apontar que: "A simples ideia é distribuída na multiplicidade de partes e condições do organismo, mas resta intacta na junção necessária das partes e funções" (BAW, p. 372). A divergência do autor das notas com relação à Kant, portanto, é posta nos primeiros momentos de sua reflexão: sua abordagem do problema entende-se como um afastamento de Kant, na medida em que o autor das notas pretende efetuar a redução da ideia de finalidade natural a um traço da própria constituição humana.

A afirmação nietzschiana de que Kant deveria ser compreendido como um filósofo filiado a uma corrente teleológica em filosofia (BAW, p. 372) está diretamente ligada a esta forma de compreensão do problema. Para Nietzsche, a defesa de uma concepção teleológica como necessária para a compreensão da natureza, tal como essa noção apareceria na Crítica da Faculdade do Juízo, para Nietzsche, só poderia ser admitida como uma maneira de definir o conceito de teleologia.

A denúncia da filosofia kantiana como uma forma de defesa da teleologia parte da compreensão de que Kant chega, em sua investigação da finalidade natural, a uma conclusão não fundamentada.

\footnotetext{
3 Crawford observa o caráter antropomórfico por trás da própria consideração da ideia de conveniência a fins, tal como Nietzsche entende essa ideia: “Ao levarmos em consideração o primeiro ponto nos planos da obra de Nietzsche, "conceito de conveniência a fins" (Begriff der Zweckmässigkeit, BAW, p. 392) note que ele qualifica a palavra conveniência a fins (Zweckmässigkeit, Crawford traduz este termo por expedience) como o conceito de conveniência a fins. Nietzsche cita Kant duas vezes a partir da Crítica da Faculdade do Juizo acerca do papel fundamental dos conceitos: 'Nós temos completa ideia apenas do que podemos fazer e cumprir de acordo com nossos conceitos'. A isso Nietzsche responde: 'o que se encontra além dos conceitos é completamente incompreensível'. Tendo em vista superar o fato de que os seres humanos se põem diante do desconhecido, eles inventam 'conceitos, os quais apenas reúnem uma soma de características aparentes, as quais, porém, não conseguem apreender as coisas'. Nietzsche então enfatiza a natureza provisional da conceitualidade com relação aos elementos básicos de uma consideração teleológica ao escrever: 'Entre estes estão força, matéria, indivíduo, lei, organismo, átomo, causa final. Estes não são partes, mas apenas juízos reflexivos"”. (Crawford, 1988, p. 110).
}

88 | Cad. Nietzsche, Guarulhos/Porto Seguro, v.41, n.2, p. 85-115, maio/agosto, 2020. 
As notas do período militar de Nietzsche: Para uma reavaliação...

Em sua análise das conclusões da Crítica da Faculdade do Juízo, Nietzsche identifica uma transposição indevida da análise da realidade fenomênica para uma realidade superior, apartada do mundo orgânico, o que representaria um salto lógico com base na pressuposição da necessidade de se considerar fins na natureza. Para o autor das notas preparatórias, portanto, Kant não teria conseguido superar a interpretação ontológica do problema teleológico.

O tratamento do problema da teleologia nas notas preparatórias, que se oferece como a transição de uma interpretação ontológica para uma interpretação eminentemente epistemológica, converge para uma forma de reflexão acerca da natureza do conhecimento e dos limites da capacidade de compreensão humana. Assim, em sua leitura, Nietzsche concebe a origem da ideia de finalidade exterior como uma superexaltação da racionalidade humana que, por meio da analogia entre a inteligência constituidora da natureza com a nossa organização, conduziria a uma compreensão da realidade segundo princípios finalísticos.

Para o jovem Nietzsche, a suposição de uma realidade organizada mediante uma inteligência exterior seria um antropomorfismo ingênuo, que faz com que se conceba a ideia de finalidade como um traço ineliminável da realidade, conduzindo inevitavelmente a uma concepção teleológica. Competiria à crítica da concepção teleológica desvelar este antropomorfismo, por meio da fundamentação da compreensão desta ideia como uma forma humana de compreensão da realidade. Nesse sentido, na medida em que a concepção teleológica diria respeito a nosso modo de enxergar a natureza e não à natureza tal como ela poderia ser em si mesma, Nietzsche aborda o problema mediante um tratamento segundo uma análise das condições de percepção das finalidades, e não de sua realidade necessária. O que, para o autor das notas, seria a pretensão por trás das aproximações racionalistas. 
Silva Filho, J. P.

Segundo a leitura apresentada por Nietzsche nas notas preparatórias, a explicação kantiana do mundo orgânico parece reclamar um recurso às coisas em si para sua justificação. Nesse sentido, o jovem autor das notas preparatórias se volta contra Kant e a favor de Schopenhauer quando afirma: "A ideia, expandida acima, confere a explicação da conveniência a fins externa. A coisa em si deve "mostrar sua unidade na aceitação de todas as partes"" (BAW, p. 373). O filósofo compreende que se a natureza apenas nos pode ser compreensível mediante a ideia de uma necessidade, ou uma propensão natural a fins, isto deveria ser creditado a uma característica de nossa forma de compreender o mundo, e não à realidade ela mesma.

A ideia de uma finalidade natural, ideia na qual Kant teria se baseado para sua defesa da adoção de um princípio teleológico norteador da investigação da natureza, aparece nessa leitura como a transposição de um elemento da consideração humana da natureza para a própria natureza. A crítica nietzschiana à interpretação teleológica kantiana, portanto, baseia-se na ideia de que a referência, ou o pressuposto da experiência humana como condição de constituição da natureza, não pode ser entendido senão como a radicalização de um caráter aleatório, como uma antropomorfização da natureza. Essa crítica, no entanto, apenas pode ser adiantada por Nietzsche na medida em que o autor julga insuficiente o recurso kantiano à distinção entre conceito explicativo e conceito regulativo. Ou seja, Nietzsche pensa que a admissão de um princípio teleológico, ainda que meramente como uma ferramenta auxiliar no estudo da natureza, torna a concepção kantiana como modelo de toda forma de defesa ingênua do princípio de finalidade externa.

Mas como compreender a relação intrínseca entre as partes e o todo em um organismo, senão por meio de uma ideia de finalidade? Assim como na leitura schopenhaueriana, Nietzsche entende que essa ação de junção seria uma ação realizada pelo intelecto, e não uma 
As notas do período militar de Nietzsche: Para uma reavaliação...

característica dos organismos. Desse modo, o autor das notas afirma: "A conveniência a fins do orgânico, a regularidade do inorgânico são acrescentadas à natureza através de nossa compreensão" (BAW, p. 373). Nesse sentido, a conveniência a fins identificada por Kant na realidade orgânica corresponderia, apenas, a uma transposição do modo humano de compreensão da natureza à própria natureza.

\section{O papel de Schopenhauer na interpretação da concepção teleológica kantiana}

A tradição de comentários da obra nietzschiana consagrou uma interpretação segundo a qual, em seus primeiros escritos, Nietzsche reproduziria muitas das ideias schopenhauerianas. De fato, encontraremos na reprodução nietzschiana de passagens da obra schopenhaueriana nas notas preparatórias material suficiente para validar esta interpretação. No entanto, as similaridades nas interpretações de Schopenhauer e Nietzsche não se confunde com uma reprodução irrefletida das ideias do autor de $O$ mundo como Vontade e Como Representação. O que encontramos na reafirmação das ideias de Schopenhauer aparece nas notas preparatórias quase que de forma instrumental, especialmente para a crítica da posição kantiana. Por outro lado, o desenvolvimento da reflexão nietzschiana conduz a uma crítica ao recurso schopenhaueriano à vontade como instância em que a ideia de unidade se fundamentaria. Nessa leitura, a compreensão schopenhaueriana da ideia de conflito na natureza como um reflexo da atuação do intelecto, que se resolveria na ideia única de vontade, é apresentada como implicando dificuldades teóricas incontornáveis, que apenas por meio do recurso a uma vontade ao mesmo tempo múltipla e una seria solucionável.

A interpretação schopenhaueriana da conformação das partes ao todo aparece em sua filosofia como resposta ao problema da adequação dos organismos em relação às pré-condições de sua existência. Nesta abordagem também é levada em consideração a 
Silva Filho, J. P.

relação entre as partes do organismo em relação ao organismo como um todo, tal como esta relação é expressa por Kant na Crítica da Faculdade do Juízo e que seria, justamente, o que fundamenta a concepção teleológica expressa naquela obra. Para Schopenhauer, o instinto animal seria a perfeita representação da figuração da finalidade na natureza. Pois os animais, embora não possam se figurar uma finalidade, por não serem racionais, parecem agir segundo uma finalidade, sua manutenção:

De maneira geral o instinto dos animais nos fornece o melhor esclarecimento para a restante teleologia da natureza. Pois, se o instinto é como se fosse um agir conforme um conceito de fim, no entanto completamente destituído dele, assim também todos os quadros da natureza se assemelham aos feitos conforme a um conceito de fim e, no entanto, completamente destituídos dele. Em realidade, tanto na teleologia externa quanto na interna da natureza, aquilo que temos de pensar como meio e fim é, em toda parte, apenas o FENÔMENO DA UNIDADE DA VONTADE UNA EM CONCORDÂNCIA CONSIGO MESMA, que apareceu no espaço e no tempo para o nosso modo de conhecimento. (Schopenhauer, 2005, p. 227).

Como se explicaria esta correlação temporal, assim como sua reciprocidade? A explicação schopenhaueriana desta finalidade natural se dá por meio da conformidade dos fenômenos em relação a uma objetividade originária da Vontade Una. Como a passagem deixa claro, toda teleologia natural seria apenas o reflexo de uma harmonia da Vontade Una que aparece no fenômeno segundo os ditames do intelecto. Se toda ideia de fim na natureza seria apenas manifestação da Vontade Una no tempo e espaço para nosso conhecimento, isto significa que a teleologia não corresponde ao modo de ser da realidade, mas apenas ao modo humano de interpretar esta Vontade Una enquanto fenômeno.

A explicação schopenhaueriana dessa relação aprofunda a suposição kantiana de uma finalidade natural, que faria convergir as necessidades das partes de um organismo às necessidades do 
As notas do período militar de Nietzsche: Para uma reavaliação...

organismo propriamente. Se Kant enxerga nos organismos uma relação recíproca de causação finalística, uma mútua dependência e conformação das partes em relação ao todo e vice-versa, Schopenhauer entende essa relação como reflexo da objetivação dos fenômenos no tempo, segundo uma mesma Ideia diretora na Vontade Una. De tal forma que, a conformidade entre as exigências para o surgimento e manutenção de cada espécie em seu ambiente assim como entre as espécies mesmas, apareceria como a expressão de uma objetivação da vontade segundo o tempo, que não é uma categoria da Vontade Una, ela mesma eterna e imutável, mas do entendimento humano:

Por conseguinte, tendo em mente nossa presente consideração sobre o modo como a objetivação da Vontade se distribui em Ideias, o curso do tempo é totalmente sem significação e as Ideias cujos FENÔMENOS apareceram mais cedo no tempo segundo a lei da causalidade, à qual estão submetidas como fenômenos, não possuem nenhum direito prévio em face daquelas Ideias cujos fenômenos apareceram mais tarde e que são, a bem-dizer, justamente as objetivações mais perfeitas da Vontade, e que têm de se adaptar às objetivações anteriores tanto quanto estas a elas. (Schopenhauer, 2005, pág. 227).

Em outros termos, se a sucessão temporal corresponde apenas a um modo do intelecto representar, então não há que se espantar a perfeita correlação entre o aparecimento de uma espécie e as condições de seu aparecimento. Mais ainda, esta relação de acomodação, não apenas se expressaria na relação entre o fenômeno precedente e o que lhe sucede, mas também de forma retrospectiva:

Nesse sentido, a explanação dada também tem de ser usada retrospectivamente e devemos não apenas assumir que cada espécie se adapta às circunstâncias encontradas previamente, mas também estas, precedendo as espécies no tempo, levam igualmente em conta os seres que ainda estão por vir. Pois se trata de uma única e mesma Vontade que se objetiva no mundo. Esta não conhece tempo algum, visto que a figura temporal do princípio de razão não pertence a ela, nem à sua objetividade originária, as Ideias, mas só à maneira 
Silva Filho, J. P.

como estas são conhecidas pelos indivíduos - eles mesmos transitórios -, isto é, aos fenômenos das Ideias. (Schopenhauer, 2005, p. 227).

Em sua interpretação, Schopenhauer pensa a relação de reciprocidade entre organismo e ambiente como algo que deve ser posto em antecipação ao surgimento do organismo, de tal maneira que: "Em conformidade com tudo isso, cada fenômeno teve de se adaptar ao ambiente no qual apareceu, e este, por seu turno, teve de adaptar-se àquele, embora cada fenômeno ocupe muito mais tardiamente uma posição no tempo". (Schopenhauer, 2005, p. 226). Nessa leitura a finalidade natural é representada pelo autor como exigência necessária nesta adequação recíproca entre organismo e ambiente. De tal maneira que, ou se pressupõe uma finalidade natural a guiar o surgimento dos organismos, ou seríamos levados a pensar que cada fenômeno natural anteciparia no tempo as necessidades dos fenômenos que lhe sucedem, e estes reciprocamente àqueles.

Ora, se a Vontade Una não está sujeita ao curso do tempo, a sucessão temporal, embora seja fundamental na compreensão dos fenômenos, não lhe diz respeito. Na Vontade Una não haveria reflexo para a aparente adequação entre os fenômenos que se sucedem, porque o tempo não tem realidade na Vontade. Se não há sucessão temporal na Vontade, não pode haver uma pressuposição de adequação entre a ordem dos fenômenos. Seria, assim, o intelecto que conferiria aos fenômenos os aspectos antecipatórios, que conferimos a toda coincidência entre um determinado conjunto de características necessárias e o surgimento da espécie mesma, dependente destas características.

O princípio de razão norteador do surgimento dos fenômenos no tempo, segundo Schopenhauer, garante o surgimento dos fenômenos enquanto conformidade a uma predeterminação antecipada na unidade da Vontade. Com isso o filósofo parece adiantar uma ideia de harmonia dos fenômenos enquanto objetivação da Vontade. Pois, em sua leitura: “Todas as partes da natureza se encaixam, pois é uma 
As notas do período militar de Nietzsche: Para uma reavaliação...

Vontade UNA que aparece em todas elas." (Schopenhauer, 2005, p. 227). A explicação da adequação das espécies ao ambiente, portanto, pressupõe a harmonia preestabelecida na unidade da Vontade, que se apresentaria para os princípios da razão segundo o aspecto subjetivo de uma teleologia natural.

Embora faça questão de interpor suas ressalvas, Nietzsche será influenciado de maneira decisiva por essa compreensão do problema da teleologia. Entre suas ressalvas encontra-se a questão, por exemplo, da manutenção da vida de um animal como princípio de finalidade, dado que o autor das notas preparatórias questiona a superioridade da manutenção da vida de um organismo em relação à manutenção de uma substância inorgânica. Seria necessário pensar que a manutenção de um ser vivo requer maior conveniência a fins do que a manutenção de uma rocha em unidade consigo mesma, por exemplo, ou a finalidade neste caso como em tantos outros apareceria aqui apenas como resultado de uma antropomorfização e de uma supervalorização da complexidade envolvida com tudo que diz respeito à vida? $\mathrm{O}$ autor das notas tende para a segunda resposta.

Nietzsche parece enxergar, nas considerações de Kant e Schopenhauer, apenas a passagem de um modo necessário de compreensão da realidade para uma suposição da própria realidade. Passagem essa com que se daria uma improcedente antropomorfização da natureza. A diferença de posicionamento aqui diz respeito à radicalidade da interpretação nietzschiana, que problematiza tanto a interpretação kantiana da necessidade de uma teleologia natural como modo de explicação da natureza, quanto a crítica schopenhaueriana a esta interpretação, que conduz o autor de $O$ Mundo como Vontade e como Representação à suposição de uma unidade da vontade como modo de justificação da correlação entre os fenômenos no tempo. Por outro lado, Nietzsche julga problemática a conciliação schopenhaueriana da ideia de conflito e a pressuposição de uma unidade na Vontade. 
Silva Filho, J. P.

Na leitura do autor das notas preparatórias, seria um grande problema da interpretação schopenhaueriana, a tentativa do filósofo de conciliar a unidade da vontade com a ideia de conflito na natureza. Isto porque Schopenhauer pensa, não apenas a harmonia derivada da unidade da vontade, mas o próprio conflito como necessário para a manutenção das espécies. Nesse sentido, nem mesmo a adaptação e acomodação dos fenômenos destroem o conflito, que é essencial à vontade, assim como a fonte das guerras intermináveis de extermínio dos indivíduos:

No entanto, a adaptação e a acomodação recíproca, dos fenômenos, que surgem dessa unidade não podem anular o conflito intrínseco anteriormente exposto, o qual aparece na luta geral da natureza e é essencial à Vontade. Aquela harmonia vai só até onde torna possível a CONSERVAÇÃO do mundo e de seus seres, os quais, sem ela, há muito tempo teriam se extinguido. Em consequência, se, em virtude daquela harmonia e acomodação, as ESPÉCIES no reino orgânico e as FORÇAS UNIVERSAIS DA NATUREZA no reino inorgânico se conservam lado a lado e até se apoiam reciprocamente, por outro lado, o conflito interno à Vontade, que se objetiva por meio de todas aquelas ideias, mostra-se numa guerra interminável de extermínio dos INDIVÍDUOS de cada espécie e na luta constante dos FENÔMENOS das forças da natureza entre si, como abordamos antes. $\mathrm{O}$ cenário e o objeto dessa batalha é a matéria, que eles se empenham por arrebatar uns dos outros, bem como o espaço e o tempo, cuja união, pela forma da causalidade, é propriamente a matéria, como foi exposto no primeiro livro. (Schopenhauer, 2005, pp. 227-228).

Na leitura nietzschiana, a suposição do mundo orgânico, entendido na acepção schopenhaueriana como representação de uma unidade harmônica, em que a própria luta pela existência desempenharia um papel importante, é rejeitada na consideração da impropriedade em se considerar uma ideia de luta dos indivíduos como compatível com a ideia de uma unidade da vontade. Com isso, a justificação para a ideia de unidade que se daria na concepção schopenhaueriana de vontade, resumida por Nietzsche na citação: 
As notas do período militar de Nietzsche: Para uma reavaliação...

"todas as partes da natureza encontram umas às outras, por que há uma vontade" (BAW, p. 373), é contraposta a uma concepção da realidade como sendo inerentemente múltipla.

A solução schopenhaueriana aparece nesta leitura como a tentativa de deslocar a questão acerca da finalidade natural, em vez de resolver o problema propriamente. Nessa leitura crítica Schopenhauer teria, através da pressuposição de uma unidade da vontade, transferido o problema da teleologia para outra realidade, em que a ideia de finalidade natural acabaria por ocasionar mais problemas. Essa divergência crítica pode ser tomada como um exemplo da complexidade da influência schopenhaueriana sobre a filosofia nietzschiana de juventude.

Naquele momento de sua trajetória intelectual, apesar do que se toma conhecimento através da leitura de $O$ nascimento $d a$ tragédia ${ }^{4}$, Nietzsche já se encontrava em um patamar crítico em relação à filosofia schopenhaueriana. Para o jovem leitor de Albert Lange, autor que influenciou de maneira profunda sua interpretação da filosofia schopenhaueriana, a sentença que resume esta filosofia seria a seguinte "A vontade sem fundamento e sem conhecimento se revela por meio de um aparato de representação como mundo" (BAW, p. 353). Na concepção crítica nietzschiana, esta sentença, enquanto resumo da filosofia schopenhaueriana, carregaria todos os vícios daquele sistema. Assim, em sua crítica à Schopenhauer, Nietzsche procura desvelar as contradições do sistema schopenhaueriano por meio da análise desta sentença à luz da obra do filósofo.

Esta crítica ao sistema filosófico de Schopenhauer ficou regisntrado nas notas sobre Schopenhauer, que pertencem ao mesmo

\footnotetext{
4. Sabe-se que a obra de estreia do filósofo foi composta à luz das influências de Schopenhauer e Wagner, também um schopenhaueriano. Essa influência aparece ali de modo explícito e não questionado, ou seja, acrítico. O que levaria a supor que naquele momento Nietzsche ainda não houvera enxergado os problemas com a filosofia schopenhaueriana. No entanto, a publicação dos póstumos daquele período nos descortinam um filósofo já bastante ciente das contradições do sistema schopenhaueriano. Testemunhos dessa tomada de consciência nietzschiana dos problemas da filosofia schopenhaueriana são o texto em estudo, assim como Zur Schopenhauer, do mesmo período e que foi publicado na mesma edição dos fragmentos póstumos nietzschianos de seu período de juventude que estamos estudando.
} 
Silva Filho, J. P.

conjunto de fragmentos de juventude que Zur Teleologie, tendo sido redigidas um pouco antes daquelas5. Nesses apontamentos, Nietzsche interpreta a filosofia schopenuaeriana como "uma tentativa de explicar o mundo por meio de um fator aceito" (BAW, p. 352), em que "a coisa em si mesma se torna uma de suas possíveis formas" (BAW, p. 352). Ou seja, segundo a interpretação nietzschiana, ao menos no momento em que redige estas notas, tratava-se de uma interpretação da realidade que toma as coisas em si como uma de suas expressões possíveis. No entanto, é evidente que Schopenhauer não teria encarado sua filosofia como uma tentativa (BAW, p. 352), na medida em que julgou a coisa em si como estando aberta para si (BAW, p. 352). De maneira que o que Nietzsche considera a falha de Schopenhauer seria este não ter conseguido encarar seu empreendimento como uma tentativa, por "não ter querido perceber as negras contraditoriedades na região onde a individualidade cessa" (BAW, p. 352).

$\mathrm{Na}$ medida em que tenta descrever a realidade em termos de "Vontade" e "Representação", Schopenhauer não teria se dado conta de que "O impulso de obscurecimento produzido pelo mecanismo de representação revela-se como mundo" (BAW, p. 352), única forma pela qual o mundo da Vontade poderia permanecer velado para o homem, posto que esta unidade não está incluída sob o principium individuationis (BAW, p. 352). Assim, se o traço fundamental da filosofia schopenhaueriana é sua descrição do mundo como representação, e como tal algo passível de conhecimento, esta hipótese repousaria fortemente na impossibilidade de se desvelar o mundo como Vontade.

Por essas dificuldades, assim como por sua imbricação com o próprio núcleo das considerações schopenhauerianas, Nietzsche interpreta este conjunto de reflexões, na medida em que foi tomado

5 As notas Zur Schopenhauer, são notas remanescentes de um texto crítico da filosofia schopenhaueriana que Nietzsche elaborou na mesma época de redação das notas Zur Teleologie. Todas as vezes que este texto for citado será acompanhado da paginação da edição organizada por Mette/Schlechta, da qual já vínhamos extraindo passagens de Zur Teleologie, e, como as citações desse, todas as traduções daquele serão de nossa responsabilidade.

98 | Cad. Nietzsche, Guarulhos/Porto Seguro, v.41, n.2, p. 85-115, maio/agosto, 2020. 
As notas do período militar de Nietzsche: Para uma reavaliação...

como um sistema, como "cheio de furos". Para o autor das notas sobre Schopenhauer, essas falhas poderiam ser exploradas com sucesso, fundamentalmente, de quatro diferentes formas. Primeiramente, em que Schopenhauer não supera Kant onde pretende superá-lo, e conserva uma concepção do em si da qual não tinha direito, pois, tal como o próprio Schopenhauer havia apontado com relação ao sistema kantiano, por conta das próprias implicações de seu sistema tal concepção deveria ser abandonada. Em segundo lugar, ao permanecer assim tão próximo a Kant, Schopenhauer apenas substitui as coisas em si daquele pela categoria de Vontade, o que, segundo Nietzsche, apenas pôde ser realizado por meio de uma "intuição poética" (BAW, p. 354), cuja derivação não possuía provas lógicas que pudessem satisfazer o próprio Schopenhauer, posto que este não fora convencido no caso da filosofia kantiana. Em terceiro lugar, Nietzsche acusa Schopenhauer de derivar os predicados de sua coisa em si de uma oposição em relação aos predicados das representações. Assim, se as representações têm como sua marca a temporalidade, a espacialidade, e a multiplicidade, a Vontade deveria ser Una, indeterminada espacialmente e eterna. Mas, como poderia Schopenhauer reclamar uma relação de oposição entre as representações e a Vontade, sem declarar tal oposição às representações como predicado daquela? A quarta crítica, que é uma consequência das três anteriores, seria mais complexa. Nietzsche a descreve do seguinte modo:

No entanto, pode-se postular, para o crédito de Schopenhauer, contra as três objeções uma possibilidade de poder tríplice: pode haver uma coisa em si, de todo modo, apenas no sentido de que na área de transcendência tudo que já foi capturado pelo cérebro de um filósofo é possível. Essa possível coisa em si pode ser a vontade: uma possibilidade que, por surgir da junção de duas possibilidades, nada mais é do que o poder negativo da primeira possibilidade, ou seja, já um bom passo em direção ao outro polo, o que

6 Diante da pretensão schopenhaueriana em ter posto termo ao sistema kantiano com seu próprio sistema, Nietzsche se questiona “(...) wie in aller Welt ein Mensch mit einem so durchlöcherten System zu solchen Prätensionen komm[e]” (BAW; Pág. 354). 
significa impossibilidade. Elevamos este conceito de uma possibilidade sempre decrescente, uma vez mais, ao admitirmos os predicados da vontade, que Schopenhauer tomava como pertencentes à ela: apenas porque uma oposição é improvável entre coisa em si e aparência, mas ainda pode ser pensada. Contra tal nó de possibilidades, todo pensamento ético poderia explicar-se: mas mesmo contra esse pretexto ético ainda se poderia objetar que o pensador que está diante do enigma do mundo não tem outro meio senão oferecer palpites na esperança de que um momento de elevada consciência porá a palavra em seus lábios. Uma palavra que oferece a chave para esse texto que repousa ainda não lido diante de todos os olhos, o qual chamamos de mundo. Seria este mundo vontade? - Aqui está o ponto em que devemos fazer nosso quarto ataque. A urdidura e a trama schopenhauerianas se emaranham em suas mãos: na menor parte, como resultado de certa falta de tática de seu autor, mas principalmente porque o mundo não se deixa prender tão facilmente ao sistema, como Schopenhauer havia esperado na primeira inspiração da descoberta. $\mathrm{Na}$ sua velhice, ele se queixou de que o problema mais difícil da filosofia não havia sido resolvido em sua própria filosofia. Ele quis dizer a questão referente às fronteiras da individuação. (BAW, p. 354-355).

Como a citação deixa claro, as notas críticas Zur Schopenhauer conduzem seu leitor à conclusão de que o sistema schopenhaueriano estaria sujeito aos mesmos argumentos que Schopenhauer teria utilizado contra Kant. Sobretudo aquele segundo o qual o que é predicado de um objeto, segundo o princípio de atuação do sujeito, não poderia ser predicado da coisa em si. Já que os atributos de atemporalidade, unidade e a falta de causa, atributos que o autor de $O$ mundo como Vontade e como Representação atribui à Vontade, mostram-se impróprios da realidade da Vontade se ela é, como Nietzsche pensa, a tradução schopenhaueriana do em si kantiano. As críticas apontadas por Nietzsche ao sistema schopenhaueriano, e que tomam parte ainda em suas notas Zur Teleologie, dão testemunho de um profundo amadurecimento de sua opinião para com a filosofia daquele autor. Como resultado deste amadurecimento surge a rejeição das tentativas de descrever o sentido dos predicados da vontade como completamente inapreensíveis e transcendentes.

100 | Cad. Nietzsche, Guarulhos/Porto Seguro, v.41, n.2, p. 85-115, maio/agosto, 2020. 
As notas do período militar de Nietzsche: Para uma reavaliação...

O problema apontado por Nietzsche como não tendo sido resolvido por Schopenhauer em sua filosofia, notadamente, o problema das fronteiras da individuação, é traduzido em Zur Teleologie como o problema dos limites da capacidade humana de conhecer. Investigação a partir da qual Nietzsche apresenta a dificuldade em atingir uma compreensão que unifica o real, para além da distinção artificial e arbitrária entre o que se apresenta de forma teleológica e o que se apresenta de forma não teleológica, como uma dificuldade essencial de toda concepção teleológica ${ }^{7}$. Para o filósofo, este problema teria certa similaridade com o problema referente à relação entre a causalidade natural e a questão da liberdade humana, como o próprio Kant houvera observado.

\section{O valor prático da crítica à concepção teleológica}

Em sua primeira crítica, na parte denominada pelo autor de Dialética transcendental, Kant demonstra de que modo a especulação racionalista acerca da imortalidade, de Deus e da liberdade transcendem os limites da razão teórica e, portanto, se põe a investigar aquilo que estaria para além dos limites da mera razão teórica. Assim, uma comparação entre a primeira e a segunda crítica mostra que a determinação dos limites da experiência humana, em comparação às exigências do agir prático, acentua um abismo insuperável entre o domínio prático e o teórico em filosofia. Estabelecendo-se assim os limites da razão teórica e colocando conceitos fundamentais para a razão prática para além desses limites, o autor parece apresentar uma barreira insuperável no interior da própria razão humana, que

\footnotetext{
7 Este problema é apresentado pelo autor nas notas quando afirma que: "A maior dificuldade é a unificação da teleologia e do mundo não teleológico" (BAW; pág. 373). A apresentação do problema, de forma pouco elaborada e demasiado abrangente, como é comum, desde que se trata aqui de um plano não levado à conclusão, pode obscurecer a importância da questão. Esta má elaboração, no entanto, logo é acrescida de uma discussão que faz compreender tratar-se aqui de um ponto fundamental.
} 
Silva Filho, J. P.

aparece ao autor da terceira crítica como uma lacuna teórica a ser superada mediante o estudo do juízo de gosto ${ }^{8}$.

A análise estética kantiana, que desemboca na questão do gosto, ou, uma faculdade de apreciação estética reconhecida, faz com que Kant entre em contato com um juízo estético fundamentado na sensação de prazer. Algo subjetivo, mas que ao mesmo tempo seria passível de ser reproduzido. Assim, a análise kantiana do gosto conduz a duas conclusões aparentemente verdadeiras, embora contraditórias, segundo as quais o gosto seria subjetivo e, ao mesmo tempo, objetivo. A objetividade do juízo de gosto, porquanto tal juízo pertença a esfera subjetiva, não seria passível de determinação objetiva.

A força do argumento kantiano repousa na sugestão de que, para que o gosto pudesse vir a ser objeto de discussão, o que implica uma possível concordância, este deve fundar-se em conceitos. Desta forma, com base na suposição de uma distinção entre coisas em si e fenômenos, suposição que surge como conclusão da primeira crítica kantiana, o filósofo teria procurado superar a dificuldade envolvida na determinação de uma certa objetividade do juízo de gosto. Para o autor da terceira crítica, a possibilidade de determinação da objetividade de um juízo subjetivo, tanto na questão da filosofia prática quanto na questão dos juízos estéticos, apenas pode se dar com base na suposição da existência de objetos necessários para a justificação desses juízos. Suposição que aqui assume um caráter apenas hipotético, na medida em que o filósofo compreende que destes não podemos ter conhecimento objetivo ${ }^{9}$.

Por outro lado, a hipótese de uma possível objetividade dos juízos de gosto contaria com uma hipótese contrária, além de bastante

\footnotetext{
80 espaço de que dispomos neste trabalho não possibilita um estudo exaustivo da teoria do gosto kantiana. Dessa forma, o que se segue, à guisa de resumo e introdução à compreensão kantiana da concepção de teleologia, apenas pretende tecer uma breve consideração dos problemas abordados por Kant na terceira Crítica, assim como uma breve reflexão acerca do lugar dos juízos teleológicos naquela discussão.

9 Esse rápido resumo do problema, justamente pela brevidade, carece de muitos esclarecimentos e aprofundamentos. No entanto, aqui pretendemos apenas oferecer uma breve apreciação dos problemas enfrentados por Kant na terceira Crítica, sobretudo, do ponto de vista da consideração nietzschiana destes problemas.
}

102 | Cad. Nietzsche, Guarulhos/Porto Seguro, v.41, n.2, p. 85-115, maio/agosto, 2020. 
As notas do período militar de Nietzsche: Para uma reavaliação...

plausível, de que, aquilo que agrada não agrada universalmente, não se podendo chegar a um consenso absoluto em termos de gosto. Esta antinomia aparentemente insolúvel, na medida em que aponta para uma tese e uma antítese igualmente plausíveis, é resumida por Kant na impossibilidade de se fundar o gosto em conceitos. Pois fica provado, na esfera da análise estética, que se o gosto deve ser tomado como algo que se funda em conceitos, ele poderia ser determinado segundo demonstrações, e, assim não seria passível de disputa. Por outro lado, se este não se funda em conceitos não é passível de disputa, igualmente, pois não seria possível alcançar uma concordância. Assim, segundo o autor da Crítica da faculdade do juizo, essa saída deveria ser considerada, ainda que a contragosto, como uma forma de libertar o juízo do gosto de sua antinomia:

Vê-se, portanto, que a eliminação da antinomia da faculdade de juízo estética toma um caminho semelhante ao que a Crítica seguiu na resolução das antinomias da razão teórica pura; e que aqui, do mesmo modo, como na Crítica da razão prática, as antinomias coagem a contragosto a olhar para além do sensível e a procurar no suprassensível o ponto de convergência de todas as nossas faculdades a priori, pois não resta nenhuma outra saída para fazer a razão concordar consigo mesma. (Kant, 2016, p. 203).

A solução para as antinomias do juízo de gosto encontrar-seia, portanto, para além dos limites do sensível. Do mesmo modo, na medida em que os juízos teleológicos se fundamentariam no "conceito de um fim na natureza", a ele também estaria ligado a necessidade de um recurso à esfera do suprassensível, da qual, segundo Kant, embora não se possa ter um conceito exato, deve-se admitir a existência. Esse recurso à esfera do suprassensível não escapará a Nietzsche, o qual rejeitará esse tipo de solução como um tipo de antropomorfização infundada. Em sua leitura, que é perpassada por uma atitude de franca hostilidade a todo recurso ao suprassensível, a solução para o problema da finalidade na natureza apenas poderia ser contemplada na identificação dos limites do conhecimento humano, que para 
Silva Filho, J. P.

Nietzsche estariam muito rigidamente demarcados, se restringindo à esfera da causalidade mecânica.

Esta interpretação do problema da conformidade a fins no reino orgânico, que o autor das notas determina como sendo ao mesmo tempo semifilosófica e semicientífica, a suposição mesma da finalidade natural estaria ligada a uma má interpretação da realidade, que teria sido motivada por uma desconsideração do papel da razão na organização dos elementos que compõem nossa forma de conceber o mundo. Nietzsche pensa, naquele momento, que o recurso a uma realidade suprassensível como forma de justificar a existência de uma finalidade na natureza estaria ligada a uma recusa em se aceitar o mecanicismo como método adequado para a investigação do orgânico. Essa recusa, por sua vez, seria decorrência de um preconceito em favor do que vive, considerado pelos investigadores precedentes como algo mais complexo do que o pertencente ao reino inorgânico.

Por essas razões, Nietzsche considera a suposição de fins na natureza uma decorrência de uma transgressão do princípio de razão mínima. Essa transgressão se daria no recurso, o qual o autor das notas pensa que teria sido utilizado pelos defensores da ideia de uma finalidade natural, a uma razão superior. Para o autor das notas, esse recurso não se justificaria, pois tal problema poderia ser satisfatoriamente resolvido com base em um princípio mais simples:

Conformidade interna a fins. Vemos uma máquina complicada, que se mantêm a si mesma e não podemos vislumbrar outra estrutura que pudesse constituir-se de modo mais simples, isto significa apenas: a máquina se mantém por si mesma, assim ela é conforme a uma finalidade. Um julgamento acerca de "uma finalidade superior" não podemos fazer. Podemos, no melhor das hipóteses, decidir acerca de uma razão, mas não temos direito a indicar se é uma razão superior ou inferior. (BAW, p. 373).

A ideia kantiana de que a forma de causalidade recíproca atuante nos seres orgânicos apenas poderia ser compreendida por meio do recurso a uma razão superior é rejeitada por Nietzsche, por 
meio da compreensão de que nessa leitura a ideia de finalidade sofre uma supervalorização indevida. Para dar sentido a esta rejeição, o autor das notas preparatórias faz uso de uma espécie de princípio de Ockham ${ }^{10}$, segundo o qual a atribuição de um princípio exterior, no caso em questão uma razão superior que pensa uma finalidade superior àquela que o homem pode compreender, não procede de uma conclusão lógica, mas de uma ilusão que atua por força de um grosseiro antropomorfismo. Este antropomorfismo consistiria na defesa de uma razão superior, defesa por meio da qual o defensor da finalidade natural nada mais faria do que pôr em prática uma exaltação da razão.

Segundo a compreensão do autor das notas preparatórias, no entanto, este tipo de afirmação de uma finalidade externa superior não se sustenta em uma análise da razão, porque "apenas temos experiência do método da natureza" (BAW, p. 374), e nunca de finalidades. Dessa maneira, quando nos confrontamos com um produto da natureza, a sua finalidade apenas nos aparece como o produto de um método sem sentido, nunca como uma necessidade lógica. Por outro lado, a ideia de uma finalidade superior apenas nos aparece quando somos confrontados com a vida. Para Nietzsche, essa dedução de uma finalidade superior na manutenção da vida não obedeceria

10 Para Guilherme de Ockham o Princípio da Parcimônia, o que ficou conhecido na tradição como Navalha de Ockham, significava que "é desperdício fazer com mais o que pode ser feito com menos". Embora não tenha sido inventado por Ockham, o princípio da Navalha teve seu nome ligado em específico a este filósofo por sua larga utilização no sistema que desenvolveu. (Junges; 2005, p. 03). Conforme nota cinco do artigo, "A expressão 'Navalha de Ockham' surgiu no século XVI sugerindo que, mediante tal Navalha, Ockham 'encurtava as barbas de Platão', numa referência direta ao dualismo que ele suprimia com sua negação da existência dos universais. Com essa concepção, as essências passavam a ser apenas elucubrações, deslocando o eixo da metafísica para um empirismo nominalista, já que Ockham dizia serem os universais apenas nomes dados às coisas, criados pela mente de seu autor, e o que realmente havia eram as singularidades e o que poderia ser experimentado pelos sentidos humanos". (Junges, 2005, p. 16).Com relação à proximidade entre as filosofias de Ockham e Nietzsche, Junges afirma: "Aqui apenas podemos comparar entre nossos dois filósofos em questão o fato de que ambos apontavam a concretude da vida como indiscutível, fundamental, renegando a metafísica como expediente para um entendimento do mundo em si. A mentira do outro mundo era paralisante, desnecessária. O viés antimetafísico de Ockham e Nietzsche denota a importância da crítica do mundo ocidental em seus escritos. (...) Quanto à existência dos universais, amplamente negada por Ockham, acreditamos ser seu posicionamento bastante próximo ao de Nietzsche. Isso porque Ockham, num viés de declarado cunho aristotélico, pensava os universais como impossíveis sob uma justificativa lógica, não passando de palavras que denominavam sentidos por nós criados, abstrações ou ficções da mente humana". (Junges, 2005, p. 14). 
Silva Filho, J. P.

a qualquer lógica, mas, talvez, a uma certa arrogância de espécie. Pois, na medida em que pertencemos ao grupo dos "viventes", possuímos um preconceito com relação ao que é vivo, sendo aqui a vida o grande segredo que reclamaria em sua explicação a ideia de uma finalidade natural:

Ficamos impressionados então com a complexidade e conjecturamos (por meio de uma analogia humana) uma sabedoria especial nisto. O que realmente é maravilhoso para nós realmente são os viventes orgânicos: e todos os meios para mantê-los chamamos conforme a fins. Por que suspendemos o conceito de conformidade a fins no mundo inorgânico? Porque temos aqui apenas unidades, não partes correlacionadas atuando umas com as outras. (BAW, p. 374).

Conforme essa interpretação, nossa ideia de uma finalidade superior advém de uma incompreensão fundamental acerca do fenômeno vida. Incompreensão esta fortemente motivada por nosso preconceito para com o que vive. Em outras palavras, a própria distinção entre o orgânico e o inorgânico nada mais seria do que o produto de nosso preconceito para com o que vive, e entre os produtos possíveis da atuação das partes da natureza também os organismos seriam uma possibilidade. Isso independente da complexidade envolvida, desde que o "acaso pode encontrar a mais bela melodia" (BAW, p. 374). Disso decorre a hipótese nietzschiana de que a vida mesma pudesse ser compreendida como o produto de forças atuando ao acaso, segundo os ditames de uma causalidade mecânica. Ou seja, independente da complexidade envolvida, tudo poderia ser obra do acaso e da atuação não finalística das mesmas forças que atuam na geração do reino inorgânico.

Nessa suposição encontramos o surgimento de uma concepção fundamental, que o uso proposital do termo "forças" procura tornar evidente, segundo a qual toda realidade que se nos apresenta de forma orgânica poderia ser produto da atuação de forças ao acaso. Assim, com a alusão ao acaso, associada à ideia da atuação de 
As notas do período militar de Nietzsche: Para uma reavaliação...

relações causais, Nietzsche opera uma explicação do surgimento do orgânico sem recorrer a qualquer instância externa ao orgânico, sem nenhum recurso a uma finalidade externa. Solucionada assim a questão do surgimento da realidade orgânica por meio do recurso a uma associação entre causalidade mecânica e acaso, restaria explicar como um ser orgânico poderia sustentar-se sem uma finalidade interna. Mas esse questionamento aparece aqui como uma questão frívola, que apenas poderia ser despertada no interior de uma concepção teleológica, que sempre suscita muitas questões sem sentido ${ }^{11}$. É nesse sentido que Nietzsche afirma: "vemos um método para alcançar um objetivo, ou mais exatamente: vemos a existência e seus meios e decidimos que esses meios são conformes a fins. $\mathrm{O}$ reconhecimento de uma razão elevada, certamente não a de uma razão superior, ainda não se põe aqui" (BAW, p. 374). Ou seja, o fato de que organismos se mantenham conforme a sua própria manutenção não implica a ideia de uma finalidade superior, porque a manutenção do organismo é um fim apenas para o organismo, e não um fim superior.

O tipo de explicação adotada por Nietzsche neste ponto de sua exposição, que toma como base uma explicação não teleológica do reino orgânico, teria como interesse mais profundo lançar as bases para uma investigação das questões naturais sem o recurso a uma realidade ideal, apartada das relações de necessidade. Essa compreensão do problema, portanto, não pode ser desvinculado de um interesse prático fundamental. Ou seja, com a eliminação da teleologia e a consequente restituição das questões orgânicas ao reino do orgânico, surgiria a possibilidade de se eliminar o mundo das ideias que, como vimos, aparece como fundamento para a solução da questão teleológica no procedimento kantiano na Crítica da faculdade do juizo. Nesse sentido, o autor das notas sobre teleologia afirma: “o colocar de lado da teleologia tem um valor prático. É apenas uma

11 Tais questões seriam, por exemplo, a compreensão do mundo como um organismo vivo e da origem do mal, questões cuja rejeição ecoara na obra madura de Nietzsche. 
Silva Filho, J. P.

questão de recusar o conceito de uma razão superior: assim já nos satisfazemos." (BAW, p. 374).

Nos parece que o ponto fundamental a ser considerado aqui é que, em Zur Teleologie, Nietzsche parece reconhecer a atuação de um princípio metafísico na tendência para a solução das questões teleológicas por meio das coisas em si. Assim, ao afastar a questão de uma razão superior, o autor entende que a solução do problema teleológico sem o recurso a uma realidade suprassensível tornaria possível a análise de questões referentes à liberdade sem o recurso a uma concepção idealista. Mesmo se o alvo de sua crítica é a ideia de uma finalidade natural, a tendência a uma explicação idealista desta finalidade não seria menos questionável.

Considerando-se o que fica dito, torna-se forçoso reconhecer que o combate às coisas em si, como uma parte fundamental do combate a uma tendência filosófica condenável do ponto de vista teórico, tem suas primeiras origens já entre as obras do período de juventude da filosofia nietzschiana ${ }^{12}$. Se é certo que, tão cedo quanto em suas notas preparatórias, Nietzsche já confronta o problema da finalidade e o associa com a possibilidade de uma explicação meramente mecânica destas, então podemos dizer que, já nesse momento, ele se opõe fortemente ao recurso a toda realidade em si, tomadas desde então como uma forma equivocada de explicação. Logo, em suas primeiras incursões pela questão teleológica, podemos enxergar uma antecipação dessa temática que se transformará no questionamento acerca do valor de concepções idealistas para a vida. Ou seja, já naquele período de sua reflexão filosófica, Nietzsche interpreta o mundo das ideias como uma criação humana, fundamentada em uma supervalorização da razão.

Contrário ao posicionamento metafísico que faz repousar "a valorização da teleologia em sua avaliação do humano mundo das ideias" (BAW, p. 375), o autor parte para uma consideração estética

12 Como atestaria também o texto crítico Zur Schopenhauer.

108 | Cad. Nietzsche, Guarulhos/Porto Seguro, v.41, n.2, p. 85-115, maio/agosto, 2020. 
As notas do período militar de Nietzsche: Para uma reavaliação...

da teleologia: "Teleologia é como otimismo um produto estético" (BAW, p. 375). Essa compreensão implica que tanto a teleologia quanto o otimismo seriam criações humanas segundo um impulso poético fundamental. Fica claro, então, que, já em seu ensaio sobre a teleologia em Kant, Nietzsche está de posse da ideia de que o mundo das ideias corresponderia apenas a um produto estético, um produto da atuação do potencial criativo humano, e que essa ideia fundamental estaria ligada a um otimismo na contemplação da realidade. Da mesma forma, o autor das notas já parece estar de posse de uma compreensão apurada do caráter interpretativo dessa forma de se considerar a realidade.

Partindo de uma avaliação crítica da questão teleológica, que toma a compreensão kantiana expressa na crítica do juízo como modelo, Nietzsche estabelece uma forte oposição à tendência idealista, que faz ver nos problemas referentes à vida uma explicação extrafenomênica. Assim, ao opor-se a este tipo de explicação, o autor entende que tanto a regularidade observada no reino inorgânico como a conveniência a fins que se observa no reino orgânico seriam produtos da apropriação da razão, e não características da realidade mesma pois: "Não temos direito a qualquer julgamento sobre a intencionalidade maior" (BAW, p. 375) e "A teleologia assim como o otimismo são produtos estéticos" (BAW, p. 375). Com este tipo de afirmação o autor das notas Zur Telelologie pretende afirmar que nem uma intencionalidade superior nem uma consideração otimista da realidade teriam fundamentos em elementos objetivos da realidade, $\mathrm{e}$ que tanto a consideração otimista quanto a consideração da realidade segundo a pressuposição de uma finalidade seriam produtos de 
uma apropriação da realidade segundo os modos da organização intelectual humana ${ }^{13}$.

Afastada a hipótese da superioridade da vida em relação à natureza inorgânica, a suposição de uma finalidade como explicação do orgânico em nada pareceria superior a uma explicação mecânica. De fato, qual a diferença entre uma explicação mecânica e uma explicação finalística da natureza, quando afastada a hipótese de uma verdade superior à que toda explicação da natureza devesse se reportar? O que está sendo colocado em dúvida por Nietzsche aqui, de fato, seria a própria validade de um juízo reflexivo teleológico. Nesse sentido, como Lopes afirma, Nietzsche se colocaria em direta confrontação à compreensão kantiana da distinção entre juízos determinantes e juízos reflexivos:

O caráter indeterminado desta categorização permite a Nietzsche questionar um dos grandes dogmas do kantismo, a antítese entre mecanismo e teleologia, ou melhor, entre juízo determinante e juízo reflexivo. Ao longo de boa parte das notas preparatórias, Nietzsche parece aderir à concepção dicotômica de Kant, que restringe o conceito de explicação ao emprego da causalidade mecânica expressa no juízo determinante. Contudo, na progressão das notas, Nietzsche toma uma direção inversa e sugere uma redução das causas mecânicas a causas finais e do uso constitutivo ao uso reflexivo da faculdade de julgar. (Lopes, 2008, p. 150).

O que Lopes sugere é que a distinção kantiana entre juízos determinantes e juízos reflexivos passa a ser questionada por Nietzsche em algum momento no desenvolvimento de seus planos para tese. De tal modo que em sua rejeição de que se possa explicar a natureza

130 termo "perspectivismo" não aparece nas notas propriamente. No entanto, é possível perceber que se Nietzsche, naquela época, não utiliza o termo perspectivismo para caracterizar uma apropriação da realidade segundo as instâncias racionais, o que corresponderia a uma falsificação da realidade, o termo é, praticamente, a única coisa que falta para efetuar uma aproximação entre o pensamento expresso nas notas preparatórias e seu posterior perspectivismo. Não é nossa intenção desconsiderar que, naquele período da obra nietzschiana, a atribuição de uma perspectividade em consideração da apropriação da realidade segundo os ditames da razão corresponde a um anacronismo. Mas, os argumentos que o autor apresenta nas notas preparatórias conduzem a uma conclusão fundamental que, sem dúvida, será retomada em seu perspectivismo, a ideia de que toda ordem que se observa na realidade corresponde apenas a uma apropriação racional da realidade, e não à realidade ela mesma.

110 | Cad. Nietzsche, Guarulhos/Porto Seguro, v.41, n.2, p. 85-115, maio/agosto, 2020. 
As notas do período militar de Nietzsche: Para uma reavaliação...

orgânica por meio de uma concepção finalística, e pela sugestão de que o reino do orgânico poderia ter sua explicação realizada apenas com o recurso ao mecanicismo, a distinção entre o uso constitutivo e o uso reflexivo da razão é questionada e, por fim, abandonada.

\section{Conclusão}

Como se pode ver, o projeto de investigação do conceito de orgânico a partir de Kant põe Nietzsche, já em 1868, em contato com uma postura próxima àquela que caracterizará o período maduro de seu pensamento ${ }^{14}$. Essa postura seria determinada pela compreensão de que as leis da natureza, ou conceitos gerais como o de "orgânico", não são mais do que ilusões produzidas pelo intelecto. Na constituição dessa compreensão entram em ação conclusões críticas contundentes, oriundas de sua reflexão acerca de $A$ história do materialismo, que terão um longo amadurecimento na obra nietzschiana e que acabarão por fundamentar sua concepção madura acerca do conhecimento, assim como da relação do conhecimento com a metafísica. $O$ fato de $o$ autor das notas referir-se diversas vezes a passagens do texto langeano para reforçar suas posições, como, por exemplo, ao afirmar que "ordem e desordem não se encontram na natureza" (BAW, p. 375), e que "atribuímos efeitos à causalidade, dos quais as causas relacionadas não vemos" (BAW, p. 375), apenas reforça a compreensão de que Nietzsche reflete longamente sobre as concepções de Albert Lange.

A rejeição da vida como elemento especial da realidade aparece nessa compreensão, como exemplo da profundidade da influência do materialismo de Lange na reflexão nietzschiana. No lugar de uma concepção otimista em relação à realidade, o autor sustenta

14 Notadamente, com as ideias expressas pelo autor no aforismo 14 de Além do bem e do mal: "Começa a despontar em cinco, seis cérebros, talvez, a ideia de que também a física é apenas uma interpretação e disposição do mundo (nisso nos acompanhando, permitam lembrar!), e não uma explicação do mundo: porém, na medida em que se apoia na crença nos sentidos, ela passa, e deverá passar durante muito tempo, por algo mais, isto é, por explicação" (JGB/BM, 14. KSA 5.28). 
Silva Filho, J. P.

uma posição segundo a qual o acaso seria a última fundamentação da existência de tudo o que aparece. Assim, ao considerar que, das inúmeras possibilidades de combinação dos elementos naturais, também o orgânico aparece como possível, o autor das notas está rejeitando toda necessidade de uma finalidade superior como forma de explicação para a vida. No lugar de finalidade, a vida aparece como tendo seu surgimento e manutenção condicionados por causas puramente materiais.

Para Nietzsche, tudo que existe deve existir, posto que deve ter as condições de sua existência impressas em seu surgimento. A aparição do orgânico não representaria, nesse sentido, nenhum milagre, mas apenas uma aparição natural de algo de cujas causas se desconhece em todo ou em parte. Por outro lado, o desconhecimento das causas que ocasionam o seu surgimento não corresponde a um milagre, mas apenas a uma limitação no conhecimento destas causas:

Coisas existem, então elas devem existir, o que significa que elas devem ter as condições para a existência. Quando o homem faz algo, estes meios fazem este algo capaz de existência, ele pensa acerca das condições sob as quais isto pode se dar. Ele chama as condições para a existência da obra acabada conveniente a fins após o fato. Portanto, ele também chama as condições de existência das coisas convenientes a fins: o que quer dizer apenas com a pressuposição de que eles surgem do mesmo modo que as obras humanas. Quando um homem sorteia um número de uma caixa e este não é seu número: ele não é nem conforme a fins e nem inconforme a fins, mas, como se diz, ao acaso (zufällig) o que quer dizer sem pensamento precedente. Porém, as condições dessa existência são dadas. (BAW, p. 375-376).

Tudo que surge no reino do orgânico pertence à realidade porque causas mecânicas determinam seu surgimento, e não por conta de um intelecto superior que determina sua existência. $\mathrm{O}$ que, de certa forma, confronta a concepção kantiana, segundo a qual a causalidade mecânica não poderia explicar o reino do orgânico. 
Assim, ao citar Kant quando diz "a organização da natureza não tem nenhuma analogia com qualquer causalidade que conheçamos" (BAW, p. 376), e "um organismo é aquilo, em que tudo é intercambiável, tanto o fim quanto os meios”. (BAW, p. 376), Nietzsche já está em condições de negar essas exigências. Ao invés de uma explicação aceitável para a origem do orgânico, o autor das notas preparatórias vê em Kant apenas uma supervalorização do racional, fundamentada em uma concepção infundada do orgânico como algo superior à natureza inorgânica.

\title{
Notes of Nietzsche's Military Period: To a Reevaluation of Influences of Youth
}

\begin{abstract}
For the elaboration of his criticism of the teleological question Nietzsche starts from a particular reading of the philosophies of Kant, Albert Lange and Schopenhauer. More specifically, his reasoning around the teleological conception of the world, which constitutes a topic of significant importance for the further development of his knowledge conception, is based on a re-reading of the positions of Kant and Schopenhauer from a scientific basis . This positioning closer to science, an achievement derived from his reading of The History of Materialism, acts as a counterpoint to the philosophical opinions with which Nietzsche comes into contact in his youth.
\end{abstract}

Keywords: Schopenhauer, Knowledge, Creation, Truth, Teleology. 


\section{Referências}

CRAWFORD, Claudia. The Beginnings of Nietzsche's Theory of Language, Monographien und Texte zur Nietzsche-Forschung, Band 19, Walter de Gruyter, Berlin-New York, 1988.

JANZ, C. P. Nietzsche biographie: Enfance, Jeunesse, Les Annees Baloises. Trad. Marc B. de Launay. Paris: Gallimard, 1984.

JUNGES, Márcia Rosane. Deus e a metafísica em Ockham e Nietzsche, Revista Controvérsia, Vol. I, nl, Ed. universitária UNISINOS- RS, Porto Alegre, JanJulh de 2005, (páginas. 01-20).

KANT, Immanuel. Crítica da Faculdade do Juízo. Trad.Valério Rohden e António Marques, $3^{\text {a }}$ edição. Rio de Janeiro: Ed. Forense Universitária, GEN, 2016.

LANGE, Friedrich Albert. A History of Materialism. Author authorized translation by Ernest C. Thomas, Ed. Baillantyne, Hanson and CO. Edinburg and London, 1875.

. Geschichte des Materialismus und Kritik seiner Bedeutung in der Gegenwart, Ausgabe WOHLFEILE, mit biography und Vorworte von Hermann Cohen, ort Iserlohn, Ed. Baedeker, Jahr Vorlage (CA 1883), Jahr erter Band 1883 Umfang Buch 1/2, XXX, 852 S. 1883.

LOPES, Rogério. Ceticismo e Vida Contemplativa em Nietzsche, Tese de Doutoramento, Faculdade de filosofia e Ciências Humanas da Universidade Federal de Minas Gerais, FAFICH/UFMG, encontrado em: http://hdl.handle. net/1843/ARBZ-7JJJLV, Belo Horizonte, 2008.

NIETZSCHE, F. Sämtliche Werke. Kritische Studienausgabe (KSA). G. Colli e M. Montinari (hrsg.). Berlim: Walter de Gruyter/Deutsche Taschenbuch Verlag, 1980. $15 \mathrm{Bd}$.

. Para Além do Bem e do Mal. Traduzido por Paulo César de Sousa. São Paulo: Ed. Companhia das Letras, 2007.

. O Nascimento da Tragédia ou Helenismo e Pessimismo, Tradução de Jacó Guinsburg. São Paulo: Ed. Companhia das Letras, 1992.

. Briefe: Kritische Gesamtausgabe (KGB). Herausgeben von Giorgio Colli und Mazzino Montinari. Berlin und New York 1975-2004.JANZ, C. P. 
As notas do período militar de Nietzsche: Para uma reavaliação...

Nietzsche biographie: Enfance, Jeunesse, Les Annees Baloises. Trad. Marc B. de Launay. Paris: Gallimard, 1984.

. Schriften der Studenten und Militärzeit - 1864-1868 (BAW), Herausgegeben von Hans Mette und Karl Schlechta, Bd. III, Deutscher Taschenbuch Verlag, GmbH \& Co. KG, München, 1994.

SCHOPENHAUER, Arthur. O Mundo como Vontade e como Representação. Trad. Jair Barbosa, São Paulo: Edit. UNESP, 2005.

Enviado: 29/01/2020

Aceito: 29/03/2020 